\title{
Flame quenching dynamics of high-velocity flames in rectangular cross-section channels
}

\author{
Ariff Magdoom Mahuthannan ${ }^{1}$, Deanna. A. Lacoste ${ }^{2}$ and William L. Roberts ${ }^{5}$ \\ Clean Combustion Research Center, King Abdullah University of Science and Technology, Saudi Arabia \\ and \\ Jason S. Damazo ${ }^{3}$ and Eddie Kwon ${ }^{4}$ \\ Boeing Research and Technology, Seattle, USA
}

\begin{abstract}
Understanding flame quenching for different conditions is necessary to develop safety devices like flame arrestors. In practical applications, the speed of a deflagration in the labfixed reference frame will be a strong function of the geometry through which the deflagration propagates. This study reports on the effect of the flame speed, at the entrance of a quenching section, on the quenching distance. A 2D rectangular channel joining two main spherical vessels is considered for studying this effect. Two different velocity regimes are investigated and referred to as configurations $A$, and B. For configuration A, the velocity of the flame is 20 $\mathbf{m} / \mathrm{s}$, while it is about $100 \mathrm{~m} / \mathrm{s}$ for configuration B. Methane-air stoichiometric mixtures at 1 bar and $298 \mathrm{~K}$ are used. Simultaneous dynamic pressure measurements along with schlieren imaging are used to analyze the quenching of the flame. Risk assessment of re-ignition is also reported and analyzed.
\end{abstract}

\section{Introduction}

$\mathbf{I}_{0}^{\mathrm{n}}$ the context of combustion hazards, the design of safety devices like flame arrestors requires a good understanding of flame quenching process. Flame quenching has been studied extensively for various parameters such as pressure ${ }^{1}$, temperature of the gas ${ }^{2}$, equivalence ratio ${ }^{2}$, wall temperature and material $l^{3}$, and orientation of the surface, compared to the flame propagation ${ }^{4,5}$. The physical mechanisms responsible for flame quenching are heat loss to the surface and wall quenching of radicals. The Péclet number, defined as the ratio of the advection rate to the diffusion rate, is traditionally used to define a theoretical basis for flame arrestors and other situations in which quenching occurs. The advection rate of a flame is governed by both the burning speed (i.e., the laminar or turbulent burning velocities), and the speed of the gas convecting the flame.

For methane-air flames, the quenching distance, defined as the minimum distance between two parallel plates for which flame propagation can be achieved, has been measured by many groups using different experimental conditions. For example, when the quenching distance is determined from freely propagating flames at ambient conditions (not confined in a constant volume vessel), the quenching distance of stoichiometric methane-air flames is $4.5 \mathrm{~mm}^{3}$. In a confined environment, where the quenching distance is determined from the non-propagation of a flame between two parallel plates, while the ignition source is located between the plates, the quenching distance is $2.5 \mathrm{~mm}^{6}$.

${ }^{1}$ Ph.D. Student, Clean Combustion Research Center, King Abdullah University of Science and Technology, Saudi Arabia

${ }^{2}$ Assistant Professor, Clean Combustion Research Center, King Abdullah University of Science and Technology, Saudi Arabia

${ }^{3}$ Physicist, Boeing Research and Technology, Seattle, USA.

${ }^{4}$ Physicist, Boeing Research and Technology, Seattle, USA.

${ }^{5}$ Professor and Director, Clean Combustion Research Center, King Abdullah University of Science and Technology, Saudi Arabia 
This value is generally admitted to be the reference quenching distance, $\mathrm{d}_{\mathrm{qref}}$, for stoichiometric methane-air flames at ambient conditions. This significant difference of quenching distances for the same gaseous mixture might be explained by a difference in the speed of the flame, but this point has never been quantitatively studied.

Although the laminar flame speed can be measured or calculated, the fluid motion induced by a deflagration wave is a function of the geometry containing the flammable gas and may be orders of magnitude larger than the flame speed. Under these conditions, the flame-wall interactions are different that those encountered when the flame propagates slowly with respect to the surfaces. Therefore, the geometry required to quench a flame propagating through a tube network or flame arrester, as well as the residual burnt gases convected downstream the quenching event should be affected by the propagation speed of the flame. The effect of the flame propagation speed on quenching in a rectangular cross-section channel is the purpose of the present study.

\section{Experimental setup}

A constant volume chamber comprising an ignition vessel, a test section of rectangular cross-section designed to produce two-dimensional flow, and a secondary vessel, has been designed for this study, see Fig. 1. The test section is $100 \mathrm{~mm}$ long and $70 \mathrm{~mm}$ wide, and the height $(\mathrm{H})$ can be adjusted from 0.1 to $7 \mathrm{~mm}$. The spherical ignition vessel has an inner diameter of $214 \mathrm{~mm}$ and the spherical secondary vessel, used to investigate possible re-ignition after quenching event, has an inner diameter of $176 \mathrm{~mm}$. The quenching of fast and slow flames have been investigated for the combustion of stoichiometric methane-air mixtures at 1 bar of initial pressure and room temperature. The ignition source is a spark, located at a distance of $75 \mathrm{~mm}$ from the entrance of test section. The spark is obtained by applying a high voltage pulse of $6 \mathrm{kV}$ amplitude and $0.5 \mathrm{~ms}$ duration. The time $t_{\text {igni }}=0 \mathrm{~s}$ corresponds to the beginning of the ignition pulse.

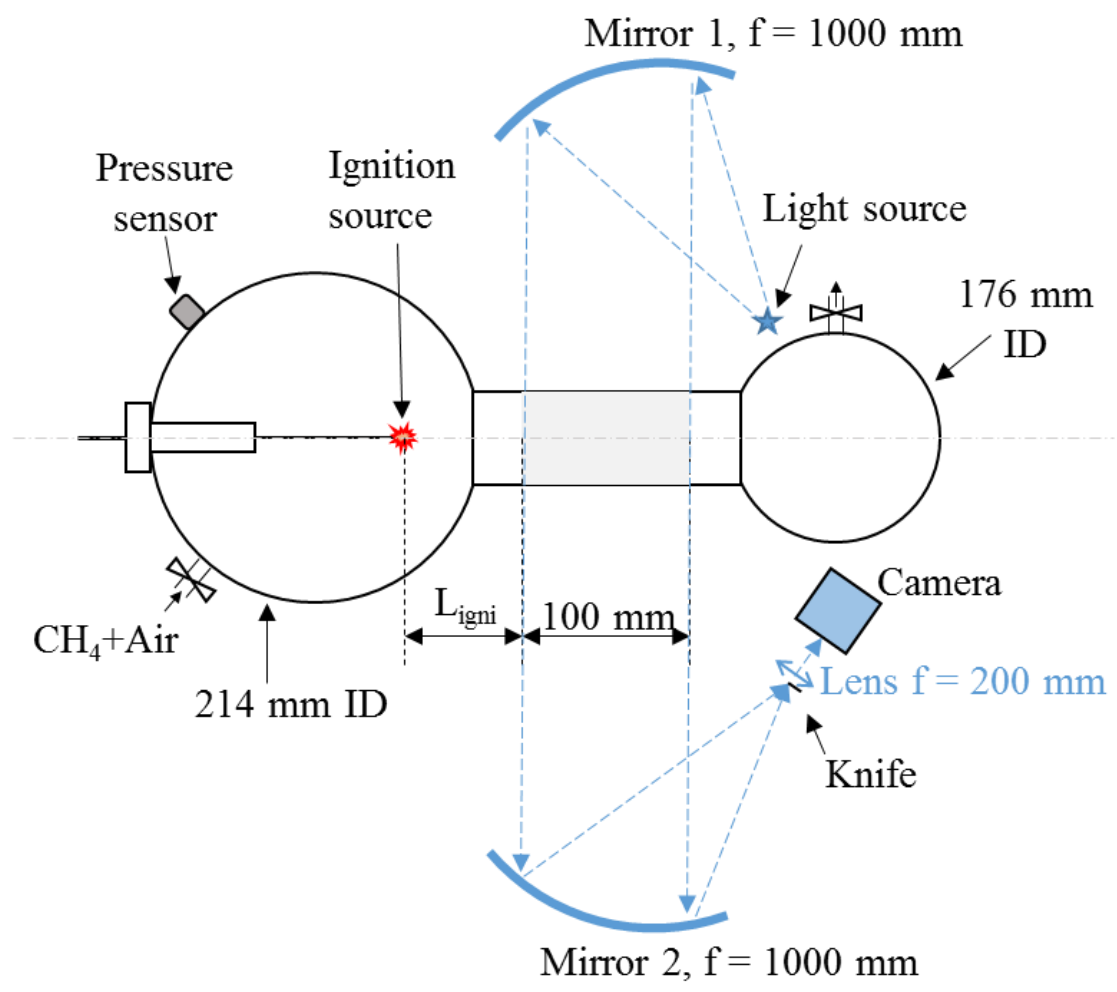

Figure 1. Schematic of the experimental setup with schlieren arrangement. 
(a)

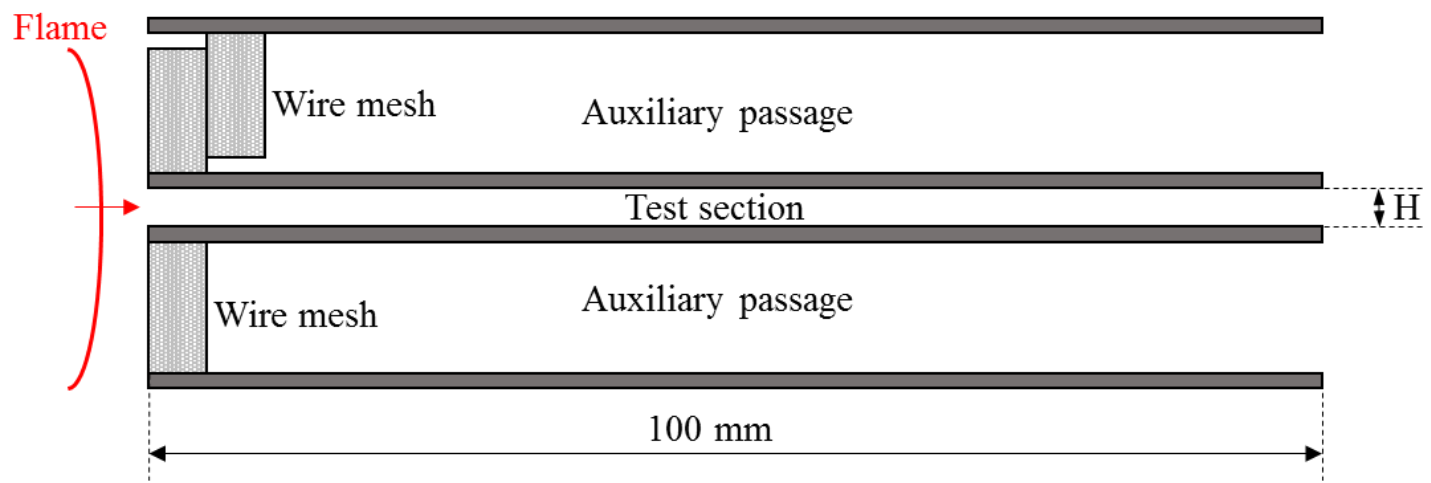

(b)

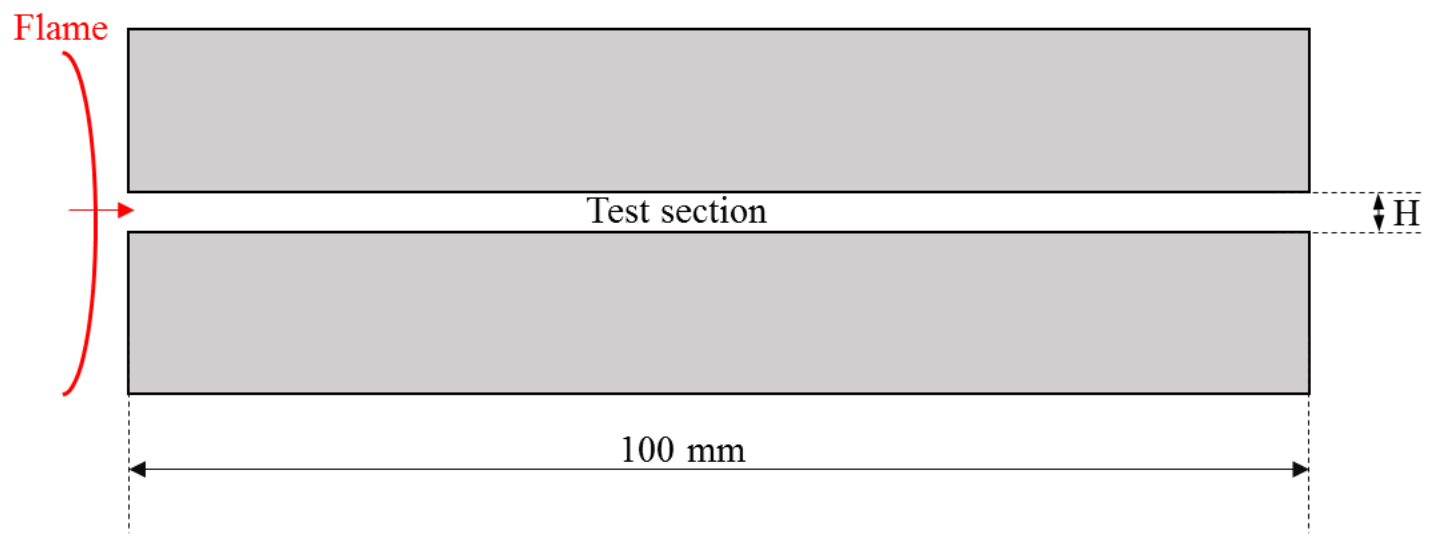

Figure 2. (a) Schematic of configuration A, and (b) schematic of configuration B.

In order to have two different propagation velocities of the flame at the entrance of the test section, two configurations, called $\mathrm{A}$ and $\mathrm{B}$, are used. Configuration $\mathrm{A}$ has a $2 \mathrm{D}$ channel with varying $\mathrm{H}$ and two auxiliary passages to allow the flow of gases. The entrance of these auxiliary passages are equipped with five layers of $0.8 \mathrm{~mm}$ square metallic mesh to ensure the flame gets extinguished and does not propagates inside. Consequently, the flow in the test section, induced by the propagation of the flame in the ignition vessel prior to enter the channel, is relatively slow. In the following parts of this paper, configuration A can also be referred as slow flames. In configuration B, only the test section connects the two main vessels. For similar conditions, the flow in the test section is significantly higher for configuration B than for configuration A. In the following parts of this paper, configuration B can also be referred as fast flames. Figure 2 shows the schematic of both configurations A and B.

The temporal evolution of the pressure in the ignition vessel is measured with the help of a piezoelectric pressure transducer (Kistler Type 6001) connected to an amplifier (Kistler Type 5018A1000). The pressure waveforms are recorded by an oscilloscope of $625 \mathrm{kHz}$ sampling rate (Tektronix, MSO 2024B). Quartz windows of $13 \mathrm{~mm}$ thickness along the channel allow optical access in the test section. Schlieren visualization has been performed with a frame rate of 15,000 fps. The light source is a white LED. The two mirrors used to obtain a parallel beam in the test section have $1000 \mathrm{~mm}$ focal length and a diameter of $200 \mathrm{~mm}$. A collimating lens, with a focal length of $200 \mathrm{~mm}$, is used to focus the light on the CCD of a fast camera (Photron Fastcam Ultima APX). The diagnostics and ignition source are synchronized with a pulse delay generator (BNC model 575).

\section{Results and discussion}

Figure 3 shows the temporal evolution of the pressure obtained for two values of $\mathrm{H}, 1$ and $1.3 \mathrm{~mm}$, for configuration A. Each plot has five sets of data for the same condition, in order to assess the reproducibility. The peak pressure obtained for $\mathrm{H}=1 \mathrm{~mm}$ is a clear indication that the flames are quenched in the channel. Indeed, the maximal pressure obtained for an adiabatic combustion would have been 8.75 bar, i.e. significantly higher than the 4.5 bar obtained for this condition. Among the five experiments, only one pressure curve records a re-ignition event in the secondary vessel, observable as a second increase in the pressure evolution, after $0.15 \mathrm{~s}$. For the experiments 
performed with $\mathrm{H}=1.3 \mathrm{~mm}$, the peak pressures are about $7 \mathrm{bar}$, i.e. close to the pressure of an adiabatic combustion. This clearly informs that there is no quenching in this configuration. In this study, the quenching distance obtained for configuration $A$ is $1.2 \mathrm{~mm}$ which is less than half $d_{\text {qref. }}$. Thus, flames propagating at about $20 \mathrm{~m} / \mathrm{s}$ (see Fig. 7a), seem to be more difficult to quench than flames propagating at a velocity close to the laminar burning speed. This result may be explained by changes in the heat transfer to the walls, while the flow in the channel remains laminar and does not significantly stretch the combustion front. Finally, even for a height of the channel as small as $1 \mathrm{~mm}$, there is a possibility of re-ignition in the secondary vessel. Therefore, for this specific constant volume cell, to strictly avoid propagation of a flame in the secondary vessel the quenching element must have a height smaller than $1 \mathrm{~mm}$. This value is geometry dependent, and further investigation will be necessary to define the physical parameter responsible for potential re-ignition. However, based on previous work from Yang et al. ${ }^{7}$ for hydrogen-air flames, the volume of the ignition chamber, compared to the volume of the secondary vessel, seems to strongly impact the re-ignition process.
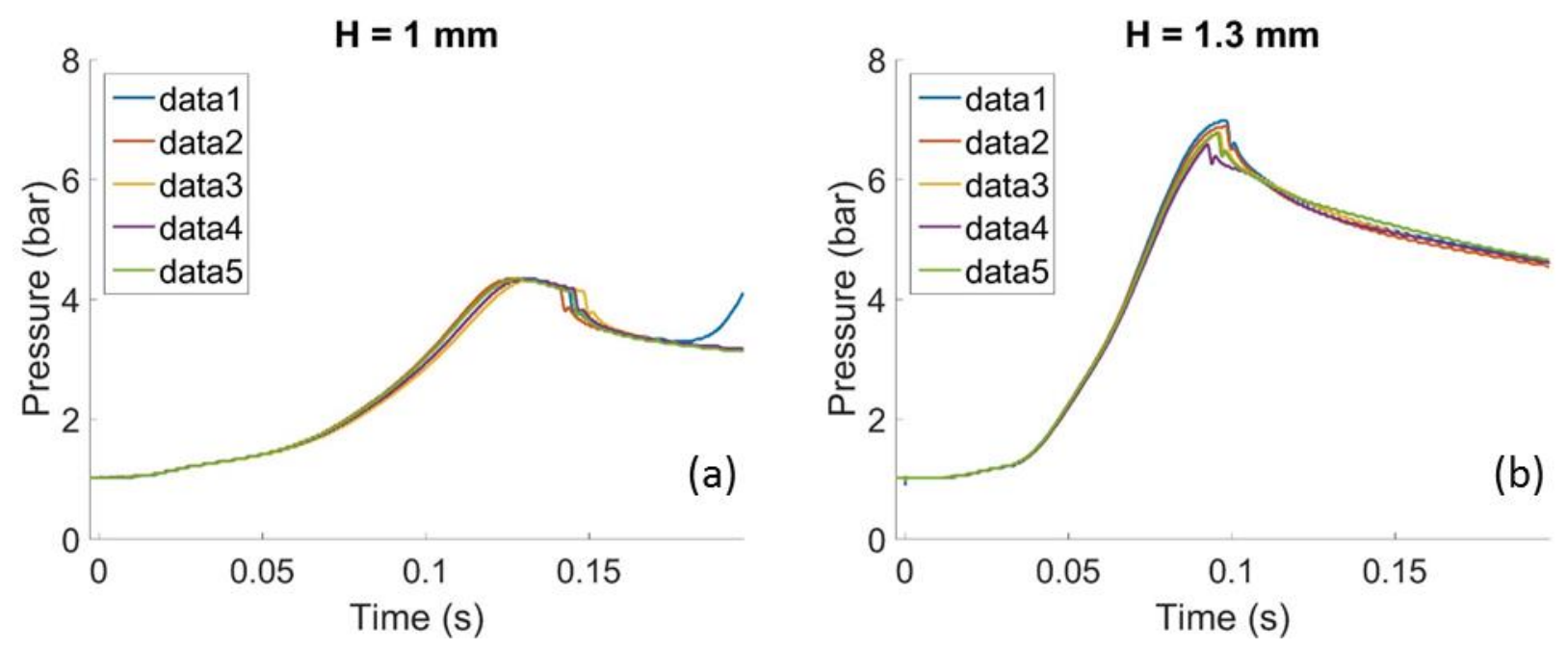

Figure 3. Temporal evolution of the pressure obtained for configuration A, for a height of the test section of (a) $H=1 \mathrm{~mm}$, and $(\mathrm{b}) \mathrm{H}=1.3 \mathrm{~mm}$.

The temporal evolution of the pressure obtained in configuration $\mathrm{B}$ for $\mathrm{H}=2.4 \mathrm{~mm}, \mathrm{H}=2.6 \mathrm{~mm}$, $\mathrm{H}=2.9 \mathrm{~mm}$, and $\mathrm{H}=3 \mathrm{~mm}$ are presented in Figs. $4 \mathrm{a}, 4 \mathrm{~b}, 4 \mathrm{c}$, and $4 \mathrm{~d}$, respectively. In configuration $\mathrm{B}$, the velocity of the flame at the entrance of the channel is about $100 \mathrm{~m} / \mathrm{s}$ (see Fig. 7b). For $\mathrm{H}=2.4 \mathrm{~mm}$ and $\mathrm{H}=2.6 \mathrm{~mm}$, the flames are always quenched, but for $\mathrm{H}=2.6 \mathrm{~mm}$ re-ignition occurs whereas for $\mathrm{H}=2.4 \mathrm{~mm}$, no re-ignition has been observed. For $\mathrm{H}=2.9 \mathrm{~mm}$, the flame can be quenched, or not quenched, depending on the event. For $\mathrm{H}=3 \mathrm{~mm}$, the flames are never quenched. Thus, for fast flames, the quenching distance obtained is similar to the well-known value of $2.5 \mathrm{~mm}$. In this case, the flow in the channel becomes turbulent (see Fig. 6d-6f) such as, even if the heat transfer to the wall are decreased, the flame is wrinkled and stretched, and it becomes less robust. In order to avoid combustion in the secondary vessel, the flame arresting devices has to be designed with height less than $2.4 \mathrm{~mm}$, for this range of velocities.

Figure 5 summarized the probabilities of quenching and occurrence of a flame in the secondary vessel, obtained for the two configurations. Figure 5a presents the effect of $\mathrm{H}$ on the probability of flame quenching and of no flame occurrence in the secondary vessel, for configuration A. The quenching of the flame is always achieved for $\mathrm{H}$ smaller than $1.2 \mathrm{~mm}$ but to avoid re-ignition in the secondary vessel, $\mathrm{H}$ should be smaller than $1 \mathrm{~mm}$. Similar results have been observed for configuration $\mathrm{B}$, as presented in Fig. 5b. For fast flames, if $\mathrm{H}$ is smaller than $2.8 \mathrm{~mm}$, the combustion will be quenched, but to avoid re-ignition in the secondary vessel $\mathrm{H}$ must be smaller than $2.4 \mathrm{~mm}$. 

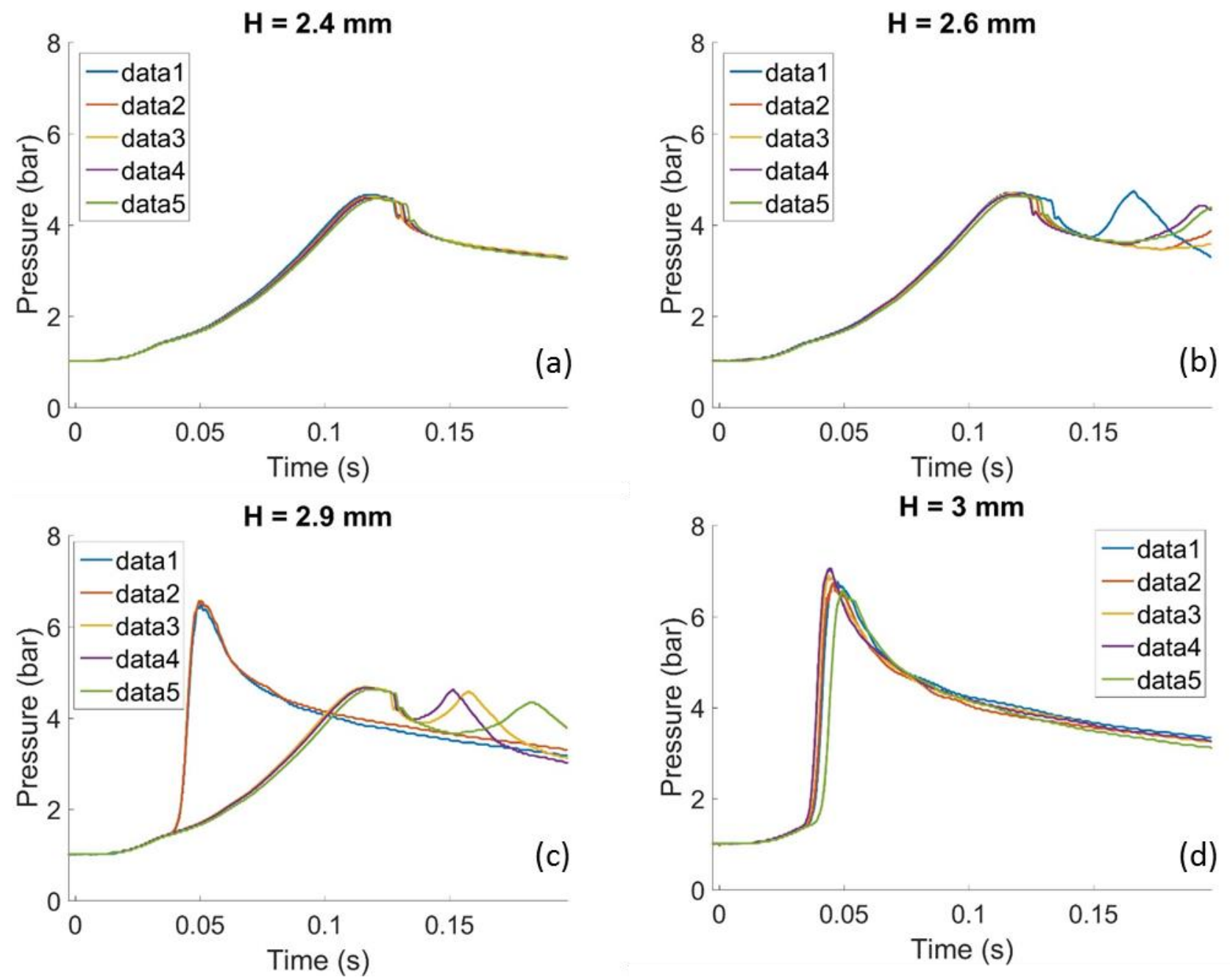

Figure 4. Temporal evolution of the pressure for configuration $B$ for, with a height of the channel of (a) $H=2.4 \mathrm{~mm}$, (b) $H=2.6 \mathrm{~mm}$, (c) $H=2.9 \mathrm{~mm}$, and (d) $H=3 \mathrm{~mm}$.
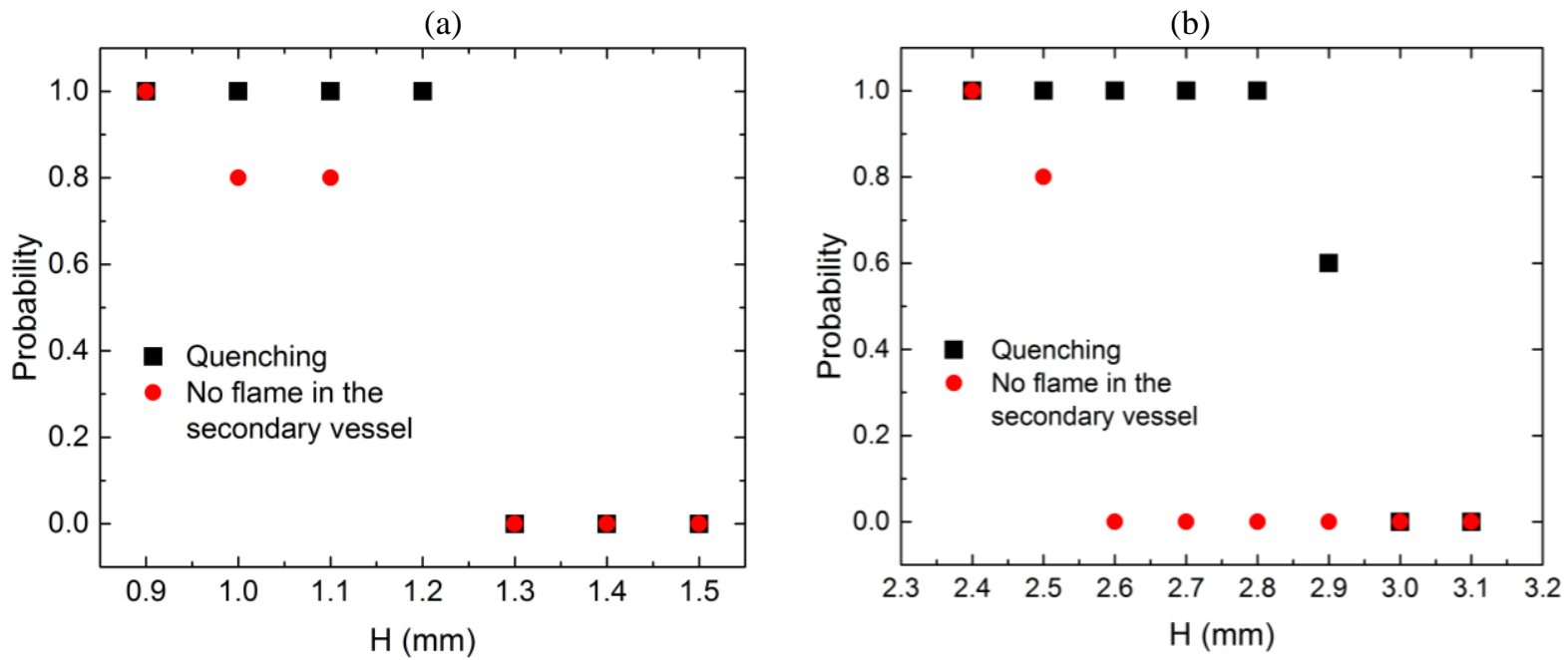

Figure 5. Probability of flame quenching and the probability of no flame in the secondary vessel for configuration A (a), and configuration B (b) 
In parallel to the pressure measurements, schlieren imaging of the flame inside the channel has been performed. These images allow the determination of the flame propagation speed in the test section. Figure 6 presents examples of successive images obtained for configurations $\mathrm{A}$ and $\mathrm{B}$, at $\mathrm{H}=1.2 \mathrm{~mm}$ and $2.8 \mathrm{~mm}$, respectively. Images (a), (b), and (c) of Fig. 6 are obtained each $1 \mathrm{~ms}$. In the image (c), the flow of hot gases in the auxiliary passage is clearly visible. Images (d), (e), and (f) in Fig. 6 are obtained each $133 \mu$ s. It is also important to notice that for both configurations, the flame enters the channel about $20 \mathrm{~ms}$ after ignition. At this time, the increase of pressure is minimal, less than 150 mbar (see Figs. 3 and 4).
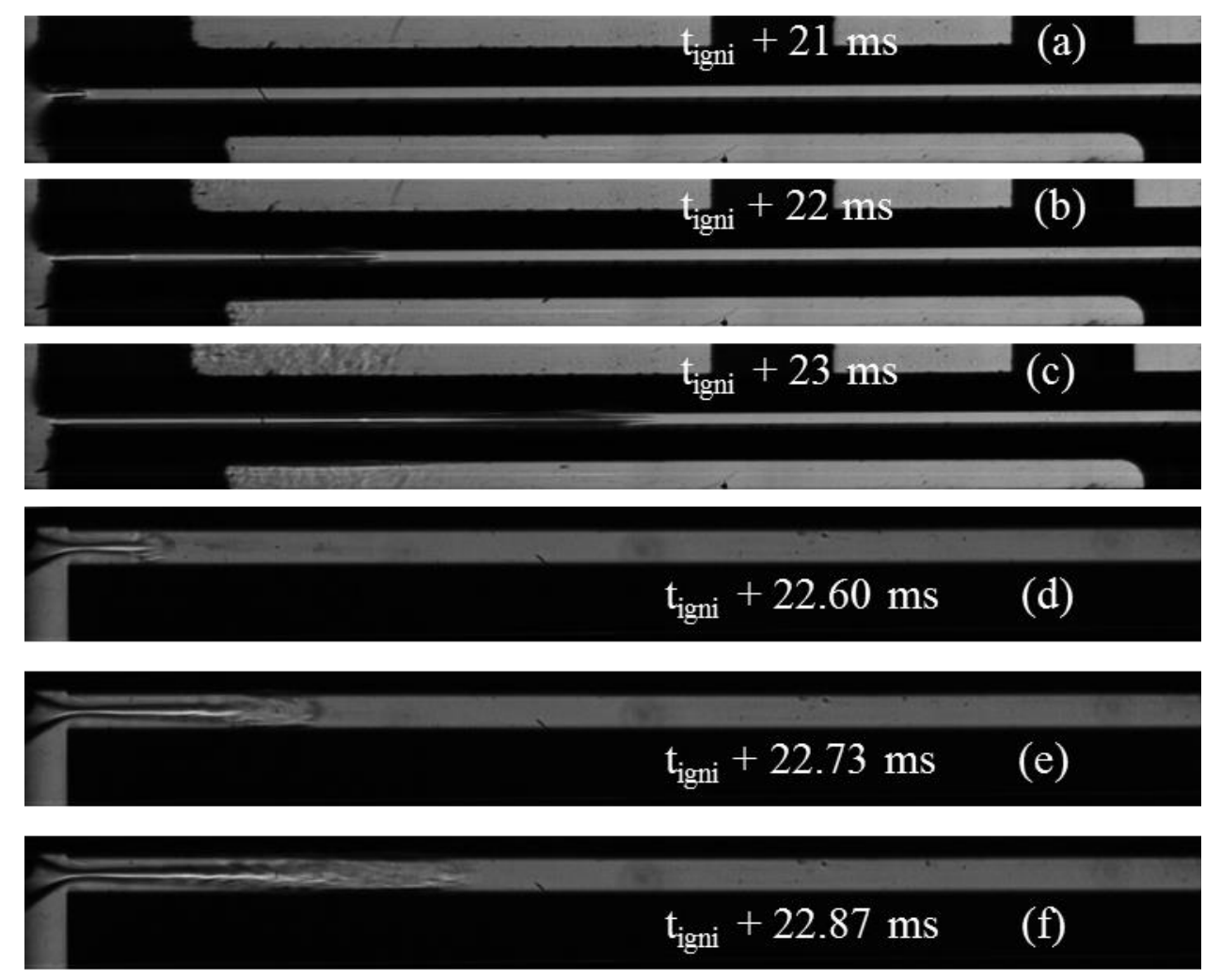

Figure 6. (a), (b), and (c) Schlieren images obtained for configuration A, with $\mathbf{H}=1.2 \mathrm{~mm}$, at different delays, and (d), (e), and (f) schlieren images obtained for configuration $B$, with $\mathbf{H}=2.8 \mathrm{~mm}$, at different delays.

Figures $7 \mathrm{a}$ and $7 \mathrm{~b}$ present the velocity profile inside the test section, calculated from the schlieren images for configurations A and B, respectively. Slow flames accelerate at the beginning of the channel (up to $20 \mathrm{~mm}$ ), for example from 20 to $25 \mathrm{~m} / \mathrm{s}$ for the fastest propagation obtained with $\mathrm{H}=1.4 \mathrm{~mm}$. Then, the velocity slowly decreases, regardless of the height of the channel, i.e. irrespective of the quenching of the combustion front. In the case of flame quenching, the schlieren images, as they only highlight the density gradients, show the propagation of burnt gases. Consequently, it is not possible to confidently determine the location of the quenching event inside the test section. Two effects can produce a decrease in the observed velocity: viscosity and local pressure differential. Viscous effects, due to the very small channel height, are believed to significantly decrease the schlieren front propagation. The auxiliary passages hasten the decrease in the pressure differential across the channel; this decrease in pressure results in the flow speed through the channel decreasing accordingly. Unfortunately, the changes in the measured pressures when the flames travel the test section are too low to be analyzed. This is due to a very small contribution to the global gas expansion of the combustion front in the test section, compared to the flame surface simultaneously propagating in the ignition vessel. In configuration $\mathrm{B}$, all the schlieren fronts travel at almost constant velocity in the channel, about $100 \mathrm{~m} / \mathrm{s}$. Similarly to configuration A, schlieren visualization does not allow determination of the location of the quenching event. As the laminar burning velocity is less than $0.5 \mathrm{~m} / \mathrm{s}$, even if the flame is quenched inside the 
channel, the propagation speed of the burnt gases induced by the combustion and the gas expansion in the ignition vessel remains high, about $100 \mathrm{~m} / \mathrm{s}$.

(a)

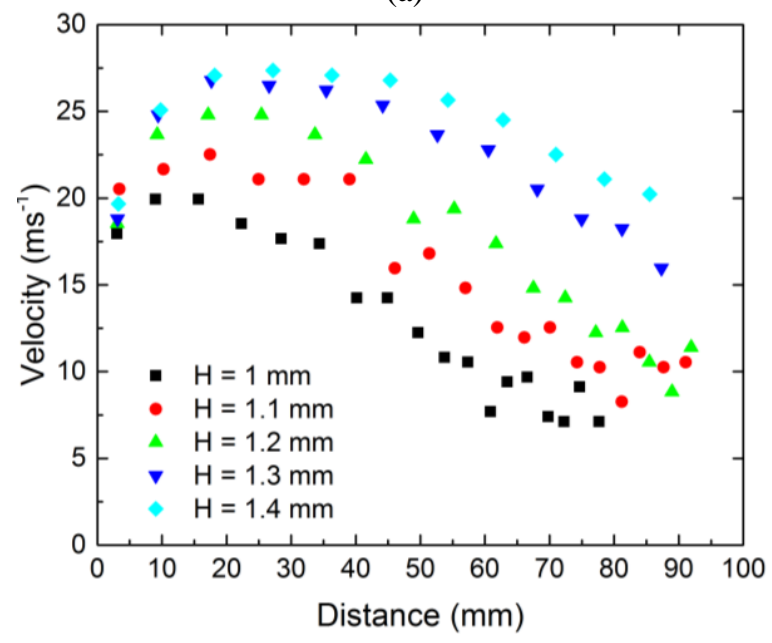

(b)

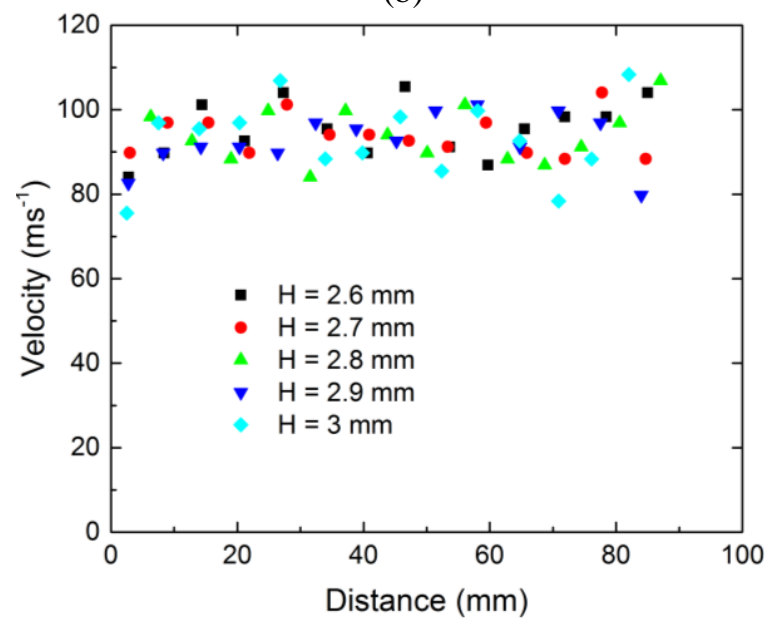

Figure 7. Velocity profile inside the test section for different $\mathbf{H}$ values in (a) configuration $A$, and (b) configuration B.

\section{Conclusion}

The effect of flame propagation velocity on the quenching and re-ignition in a secondary vessel has been studied. The measured slow flame (velocity around $20 \mathrm{~m} / \mathrm{s}$ ) quenching distance is $1.2 \mathrm{~mm}$, i.e. less than half the reference quenching distance $\mathrm{d}_{\text {qref }}$ obtained for ignition between two parallel plates ${ }^{6}$. In addition, in order to avoid reignition in the secondary vessel, the height of the channel should be smaller than the quenching distance. For this cell geometry, to be free from combustion hazard in the secondary vessel, the height of the channel should be $16 \%$ smaller than the quenching distance. However, it can be expected that the relative volume of the ignition vessel and the secondary vessel play an important role in the determination of a safe height for the channel.

The fast flames (velocity around $100 \mathrm{~m} / \mathrm{s}$ ) are easier to quench than the slow flames $(20 \mathrm{~m} / \mathrm{s})$. Indeed, their quenching distance is $2.8 \mathrm{~mm}$, which is more than two times larger than the quenching distance of slow flames. Similarly to slow flames, the channel height should be decreased by at least $16 \%$ to avoid re-ignition in the secondary vessel. This value is also geometry dependent and may be different for other cell geometries.

The velocity of the flame (or the burnt gases) inside the channel is mostly driven by the combustion in the ignition chamber rather than the combustion in the channel itself. For configuration A where auxiliary passages allow pressure equilibrium between the two vessels, the velocity in the test section decreases due to viscosity. For configuration $\mathrm{B}$, the flow in the $2 \mathrm{D}$ channel is mainly driven by the combustion in the ignition chamber. As there are no auxiliary passages to release the pressure, this combined effect keeps the velocity inside the test section high and constant.

\section{Acknowledgments}

The research reported in this publication was supported partly by the Boeing Company and partly by Center Competitive Funding from King Abdullah University of Science and Technology (KAUST). 


\section{References}

${ }^{1}$ D. Bradley, M. Lawes, Kexin Liu, R. Woolley, The quenching of premixed turbulent flames of iso-octane, methane and hydrogen at high pressures. Proc. Combust. Inst. 31 (1), 1393-1400, 2007

${ }^{2}$ R. Friedman and W. C. Johnston, The Wall-Quenching of Laminar Propane Flames as a Function of Pressure, Temperature, and Air-Fuel Ratio, J. Appl. Phys. 21, 791, 1950

${ }^{3}$ K.T. Kim, D.H. Lee, S. Kwon, Effects of thermal and chemical surface-flame interaction on flame quenching, Combust. Flame 146 (1-2), 19-28, 2006

${ }^{4}$ A. Dreizler, B. Bohmb, Advanced laser diagnostics for an improved understanding of premixed flame-wall interactions, Proc. Combust. Inst. 35 (1), 37-64, 2015

${ }^{5}$ S. Asano, S. Ikeda, T. Kagawa, C. Youn, Visualization of behaviors of propagating flame quenching for hydrogen-air gas mixture. , J. Visualization 13(2), 107-119, 2010

${ }^{6}$ M.E. Harris, J. Grumer, G. von Elbe, B. Lewis, Burning velocities, quenching, and stability data on nonturbulent flames of methane and propane with oxygen and nitrogen: Application of theory of ignition, quenching, and stabilization to flames of propane and air, Symposium on Combustion and Flame, and Explosion Phenomena, 3 (1), 80-89, 1948

${ }^{7}$ S.Y. Yang, S.H. Chung, H.J. Kim, Effect of pressure on effectiveness of quenching meshes in transmitting hydrogen combustion, Nuclear Engineering Design 224, 199-206, 2003 